\title{
A chefia mura e a conjunção de todas as turmas em uma
}

\author{
Fernando Augusto Fileno ${ }^{1}$ \\ Universidade de São Paulo
}

Resumo: A questão da chefia ameríndia traz em seu âmago uma redefinição sobre o que é espaço político e que outros modos de relação são possíveis entre chefia e grupo. Esse artigo volta-se para essa definição a partir da etnografia dos Mura, grupo indígena de língua mura, hoje falantes do português. A agência dos tuxaua mura existe como meio para manter as pessoas daquele lugar, naquele lugar. A aldeia se faz dos laços criados entre as pessoas e com o lugar em que elas vivem, porém, esses laços se estendem para além de fronteiras desse território. A aldeia não é o fim, nem limite desses laços, mas são eles que o tuxaua tenciona controlar para lograr que a aldeia siga existindo enquanto espaço de alegria/vida e não apenas como um ponto no mapa da memória daqueles que se dispersaram.

Palavras-chave: mura, chefia, política ameríndia, Amazônia.

${ }^{1}$ Mestre pelo programa de pós-graduação em Antropologia Social da Universidade de São Paulo. Possui graduação e licenciatura em História pela Universidade de São Paulo (2012), atualmente realiza atividades junto ao CEstA/USP, Centro de Estudos Ameríndios, do qual faz parte como pesquisador. 


\title{
The leader mura and the conjunction of all the turmas in a single
}

\begin{abstract}
The question of Amerindian leadership has at its core a redefinition of what is political space and what other modes of relationship are possible between leadership and group. This article turns to this definition from the ethnography of the Mura, indigenous group of mura language, now speakers of portuguese. The agency of the tuxaua mura exists as a means to keep the people of that place in that place. The village is made of the bonds created between people and where they live, but these ties extend beyond rigid boundaries. The village is not the end, nor the limit of these ties, but it is they that the tuxaua tries to control to ensure that the village continues to exist as a place of joy / life and not just as a point in the map of the memory of those who have dispersed.
\end{abstract}

Keywords: mura, leadership, ameridian politics, Amazônia.

\section{La jefatura mura y la conjunción de todas las turmas en una única}

Resumen: La cuestión de la jefatura amerindia trae en su interior una redefinición sobre lo que es espacio político y que otros modos de relación son posibles entre jefatura y grupo. Este artículo se dirige a esta definición de la etnografía de los Mura, grupo indígena de lengua mura, hablantes de portugués de hoy en día. La agencia de los tuxaua mura existe como medio para mantener a las personas de aquel lugar en aquel lugar. La aldea se hace de los lazos creados entre las personas y con el lugar en que ellas viven, sin embargo, esos lazos se extienden más allá de fronteras rígidas. La aldea no es el fin, ni límite de esos lazos, pero son ellos que el tuxaua desea controlar para lograr que la aldea siga existiendo como espacio de alegría / vida y no apenas como un punto en el mapa de la memoria de aquellos que se dispersaron.

Palabras clave: mura, jefatura, política ameríndia, Amazônia. 
$\mathrm{O}$ "tuxaua cuida da aldeia como quem cuida de sua casa", havia me dito o cacique diante de uma questão que constrangia os ânimos dos moradores da aldeia Sapucaia. Dizia em um tom de autoridade, mas cuja ciência da afirmação revelar-se-ia mais próxima da origem do fato do que da atualidade do contexto. A grande maioria das aldeias do rio Igapó-Açu registra em seus históricos uma narrativa paralela àquela dos seus chefes. Único em cada aldeia, o tuxaua é o chefe político, cuja palavra e influência circunscrevem-se aos limites da sua comunidade. O exercício do poder político inerente à instituição da chefia ganha graus variados, conformando-se ao sentido dado pela pessoa que se arvora atrás dessa função. Nossa descrição trará luz à constituição dessa posição nas aldeias do Igapó-Açu, bem como a narrativa da trajetória de alguns dos agentes dessa função com a intenção de oferecer uma contribuição etnográfica ao tema da chefia ameríndia.

Por muito tempo a questão política dentro da antropologia girou em torno da referência do Estado como expressão acabada desse modo de ação e pensamento. Como um espaço de poder vinculado pela agência humana, ele era passível de ser discernido entre diferentes grupos humanos através de uma perspectiva progressiva, passando daquelas sociedades sem poder político, até aquelas nas quais ele emergiu como Estado. Nossa sociedade então, ofereceria o modelo último dessa evolução em que o Estado, como representante de toda a sociedade, concentraria para si o monopólio de seu poder. Poder que seria entendido única e exclusivamente como sinônimo de coerção. Discussão que é colocada pela obra de Pierre Clastres e seu projeto para uma antropologia política, buscando conceber as sociedades primitivas não pela mácula da falta, mas antes revertendo o que para nós seria uma ausência e delineando-a em seus próprios termos. Se o poder político aparece para o pensamento Ocidental como o espaço de proeminência da violência, Clastres propõe uma revisão dessa máxima através do que ele alcunha como "Revolução Copernicana" (2003 [1974]). Lançando uma mirada para o material etnológico sul-americano e com base em suas próprias experiências de campo, Clastres propõe entender o espaço político como um lugar de inibição do político enquanto poder, sua neutralização consciente em favor dos interesses do grupo. O que os Mura nos dizem sobre a questão é o interesse e matéria desse artigo.

Os Mura, a quem nos reportamos, habitam o rio Igapó-Açu, pertencente ao interflúvio do Rio Madeira, dentro da T.I. Cunhã-Sapucaia, localizada no município de Borba (AM). Habitantes também do complexo hídrico dos rios Amazonas, Madeira e Purus, bem como residentes em diversos municípios da região. Para eles, o índio antes de tudo é desconfiado, uma asserção que se repetia à visita de cada nova aldeia durante meu trabalho de campo. Na aldeia Jutaí essa sentença se asseverou ainda mais diante da recepção daqueles que nada sabiam sobre mim. Fixada já na boca do rio, foi nela que presenciei também a desconfiança dos membros de uma comunidade para com seu chefe. Era ocasião de uma reunião convocada entre os moradores para discutir a presença de um estranho - o antropólogo - circulando entre seus lares. A pauta que deveria se fiar na discussão sobre as intenções de quem poderia oferecer alguma ameaça à vida daquelas pessoas, desdobrou-se na tensão que existia de antemão entre chefia e moradores. O que se questionava era a indiferença do tuxaua à chegada de um desconhecido na comunidade, o qual desconfiava da exigência de seus detratores. Para ambos os lados, a dificuldade de se tomar ciência sobre um desconhe- 
cido era dada pela inexistência de convívio prévio com aquela pessoa. Tensão que distribuía o mesmo peso dessa responsabilidade sobre ambos os lados e da qual se entrevia a desconfiança latente que existe entre o tuxaua e o restante da comunidade. $\mathrm{O}$ que esse relato tem de importante se confirmará no decorrer desse texto, o que nos interessa agora é como se faz uma aldeia e, por conseguinte, seu chefe.

\section{O tuxaua e os laços com sua aldeia}

O primeiro tuxaua ou peara de uma aldeia é, geralmente, o patriarca da primeira família que se estabeleceu naquele pedaço de terra. O cimo de um barranco que lhe agradou e cuja vista para o rio não seria comprometida em épocas de cheia. Próxima a igarapés que lhe garantissem o fruto da pesca e a salvo de pragas como a saúva que lhe proveriam a colheita da roça. Uma escolha diretamente relacionada à qualidade de vida que se espera para si e para os próprios filhos. Um projeto que anunciaria também a continuidade de seu legado, cuja sorte seria deixada para um filho quando não alcançasse mais condições para exercê-la. O filho elegido seria o depositário da confiança, dada não para aquele momento, mas criada de berço e mantida pela criação e pela convivência. Logo, menos que um argumento genealógico, a eleição do sucessor para o cargo de liderança era baseada na relação cotidiana e construída ao longo do tempo entre o atual e o futuro chefe ${ }^{2}$.

Antes de chegar à posição de chefe de uma aldeia, o tuxaua foi pai de uma família. A aldeia, logo, surgiria em torno desse núcleo familiar cujos laços se fincariam naquela terra e com os lugares e seres que ao redor dela coexistem. Aquele espaço seria o vetor de uma complexa "rede de conexões entre viventes" (T/terra, 2017, p.27). A extensão dos laços geraria novas casas que aos poucos formariam um conjunto habitacional, produzindo um espaço de convivência com a diferença humana e não humana, baseada nas relações cotidianas. A fundação da aldeia, tanto quanto sua existência no tempo depende em parte da agência política dos tuxauas (pearas), os chefes que manipulam as forças de atração, concentração e dissensão em torno de suas figuras (Amoroso, 2013: 103).

A gênese das cerca de 11 aldeias existentes no Igapó-Açu acompanha uma narrativa semelhante. Elas surgem de um primeiro assentamento que dá origem a novas casas a partir do matrimônio dos filhos do primeiro casal. Novas famílias podem aportar na aldeia a partir de laços estabelecidos em outros tempos, mas essa não é a regra. Dentro desse modelo de crescimento novos núcleos familiares são gerados, criando-se aglomerados que se distinguem como facções residenciais ou turmas, como são cunhadas no idioma local. O núcleo duro desses conjuntos eram as respectivas "casas dos pais", definidas como eixos que

\footnotetext{
${ }^{2}$ A questão sucessória abre espaço aqui para comparação com outros povos indígenas, dentro da literatura as populações alto-xinguanas são referidas pela importância que colocam sobre o tema da chefia. O problema da sucessão envolve um alto investimento tanto da liderança atual como da própria comunidade sobre o futuro chefe. Ali também, o argumento genealógico é mobilizado, mas tão importante como ele é a construção social do líder. Diz-se então, que existe uma "substância nobre" (Barcelos, 2008) que é transmitida através da filiação àquele que será ungido futura liderança, mas da mesma forma, esse pré-candidato precisa ser feito chefe ao longo da sua vida (Guerreiro Junior, 2012). A ênfase na feitura, remete à mesma dada pelos povos amazônicos ao processo de "fabricação do corpo" (Seeger et all, 1979), a condição do chefe no Alto Xingu é "visível em seu corpo e audível pela qualidade de sua fala" (Barcelos, ibid.: 262). Colocar o mesmo problema da construção social do chefe para os Mura exigiria novas pesquisas, mas um detalhe que deve ser sublinhado e que aponta para esse fim é o papel da influência dos ex-chefes sobre a atuação dos chefes atuais. Algo que diferentes contextos realçaram em diferentes aldeias, fato que não pode deixar de levar em consideração a prominência do laço de filiação desses casos.
} 
congregavam em torno de sua órbita o grosso das casas individuais da família extensa. Constituídas por parentelas bilaterais, congregavam em torno de si a reunião do conjunto dos sibblings, seus filhos e filhas casados e suas respectivas proles segundo uma tendência uxorilocal de residência. Eram casas das quais outras se desdobravam, extensões descontínuas, unidas não pela estrutura de suas construções, mas pelos laços sociais que entrelaçavam as pessoas que as habitavam. Cada uma das "casas dos pais" é um centro, o espaço de concentração das atividades de cooperação econômica, dos momentos de comensalidade, dos encontros sociais, em suma, o espaço da "convivialidade" [conviviality] (Overing e Passes, 2000).

A casa do tuxaua é mais um desses centros ao redor da qual aos poucos a aldeia se constrói, fazendo-se através das alianças matrimoniais estabelecidas entre as outras comunidades. Apesar da tendência matrilocal de residência pósmarital, o que se vê é um terreno para o jogo de forças políticas entre as casas com maior força, diríamos influência, para agregar em torno de si seus filhos recém-casados. Nessa arena, o padrão da formatação das comunidades repetia o mesmo padrão Piaroa: a grande aldeia parecia guiar sua formação pela regra da aliança, enquanto as pequenas povoações locais eram orientadas em torno do conjunto dos sibblings (Overing, 1975: 118). O tuxaua é então em um limite inferior, o pai de uma turma, quanto pode ser em um limite superior, o sogro das outras, demandando para tanto, a alimentação contínua dos laços de criação de seus filhos e a habilidade política para relacionar-se com seus afins.

Quando questionamos o significado da palavra peara, o nome tradicional da função que ostentam os tuxaus mura, a resposta costumeira contemplava a alegoria de uma vara de porcos do mato, para nos explicar que peara é aquele que vai à frente, cuja coragem é condição para a liderança, como o animal que vai a frente de uma vara de porcos (Amoroso, 2013: 95). A mesma metáfora que os Jarawara utilizam para falar de si próprios enquanto grupo liderado por um chefe (Maizza, 2012: 183-184). Uma definição que se estende para além da Amazônia ao que percebemos quando verificamos a mesma constância na filosofia política ameríndia que Lévi-Strauss encontrou na resposta de um chefe nambiquara. Esse, por sua vez, repetia aquela narrada por Montaigne em 1560 de um indígena que, como chefe, dizia que seu privilégio "constituía em marchar na frente em caso de guerra" (Lévi-Strauss, 1957 [1955]: 329)3.

Tanto a imagem, como a definição nos trazem a postura típica de quem guarda o grupo, atributo que, entretanto, não se reduz a uma posição estratégica que demanda o seu preenchimento imediato, mas também é conferida pelas características daquele que a detém. Revelador nesse sentido foi o comentário de um homem que notava o vôo de um pássaro (não identificado) enquanto estávamos no rancho: "olha o tamanho dele, deve ser o peara do grupo". Do mesmo modo, o tuxaua mura seria aquele que está adiante do todo, seu posicionamento à frente coloca-o na liderança como denominador comum do coletivo. Sua postura parece denotar um ideal de dono, como transparece a associação ao bando de bichos, como se aquele que vai à frente fosse dono daquele agregado. Há que se sublinhar também que quem assume o cargo de tuxaua o faz por atributos que o diferenciam do grupo, não necessariamente relacionados com a força, como se suporia do maior pássaro de uma revoada. $\mathrm{O}$ fato que o coloca como fundador da aldeia, não lhe assegura, contudo, a capacidade para condução a

3 Sobre o tenetãmõ, a noção que daria conta da posição do "líder" entre os Araweté, Eduardo Viveiros de Castro sublinha o mesmo princípio sobre o exercício da chefia. O líder, como o indica o significado do termo tenetãmõ, é quem está "em primeiro lugar", logo, o chefe seria aquele que inicia algo, toma a iniciativa, seja um empreendimento comum ou a própria existência de uma aldeia (1986: 301-302). 
mesma. Exige-se do chefe que ele seja um chefe, mais exatamente, que ostente as habilidades que o grupo espera serem utilizadas em benefício do coletivo. Encargos que se assemelham a de tantas outras chefias na América indígena. A "função-Eu" da qual Tânia Stolze Lima (2005: 113) se utiliza para descrever a categoria do chefe entre os Yudjá, povo tupi do médio Xingu, nos guia na tarefa de descrever a função-mura da chefia. O termo yudjá para chefe, o iju'a, glosado como "dono da aldeia", diz respeito àquele que, para além da iniciativa de fundação da aldeia, é dono de seus seguidores, dono das palavras, dono da casa do cauim, onde se realiza a atividade pela qual os Yudjá se definem, o consumo de bebida fermentada.

A renúncia ao grupo prorromperia o debulho do mesmo, o esfacelamento da aldeia e a dispersão dos aldeados. Essa visão desastrosa nos convoca a repensar a imagem do chefe como dono do grupo. Pois, se o chefe mura é o responsável pela fundação da aldeia por obra do acaso, sua liderança requer a realização de um bom trabalho. Sejam bons ou maus chefes, sempre circularão comentários sobre suas ações e intenções, por essa razão, o bom juízo sobre a chefia jamais é unânime. Não podemos dizer que o tuxaua mura seja o dono da comunidade, sendo mais o dono da iniciativa que a criou, assim como o porco/queixada não é o dono do coletivo, estando mais para o dono do caminho criado pelo seu protagonismo e pelo qual o grupo irá passar. Ambos existem como pioneiros, artífices de uma ação que criou movimento e tirou o grupo de sua estagnação e por isso, responsáveis pela mudança. Não é à toa que uma das maneiras usadas para definir o trabalho do chefe era movimento. A aldeia, historicamente erguida pela família do chefe e por obra de seus desígnios, surge como a convergência de seus desejos. Um projeto que não necessariamente contempla ou acarinha as pessoas que vivem lá, seus cunhados/as, genros e noras e mesmo, seus filhos, netos/as e demais agregados, os quais têm sob os pés não o território de origem da aldeia, mas seus interesses pessoais. Viver junto é um desejo e não uma obrigação. Reside nesse ideal, o principal desafio do tuxaua, assim como seu espaço de manobra: a conjunção em um mesmo lugar de desejos alheios independentes e a necessidade de fazê-los confluir segundo uma mesma direção. Os casos de campo relacionados ao desmembramento de aldeias que traremos em seguida são claros quanto a essa fórmula.

Primeiro daremos conta do caso da cisão da aldeia Pacovão. Não havia dúvidas sobre o tom da cisma interna que havia desencadeado o nascimento de dois novos conjuntos comunitários. A aldeia havia se desagregado em outras novas aldeias: aldeia Mura e aldeia Nova Morada. Partição deflagrada por interesses comerciais, mais uma disputa relacionada aos projetos de turismo que vem ganhando expressão no rio Igapó-Açu nos últimos anos4. Contudo, a força daquela separação havia, igualmente, sido alimentada pela saída do antigo chefe e a outorga do cargo para seu filho alguns anos antes. Figura considerada inepta para função, cujo trabalho/movimento não havia alcançado a robustez que se exige de uma chefia, pois um chefe é como um "mastro", dizia-me o antigo tuxaua: "se derruba o mastro ele cai. Ele tem que tá no teto, o tempo todo, todo duro", comparação que lhe trazia risos. Essa mesma tradução é mobilizada pelo termo -warah que identifica os chefes kanamari, assim como pela definição do anetü, os chefes kalapalo (Costa, 2007; Guerreiro Junior, 2012). Segundo o primeiro autor, a tradução englobaria também os termos chefe/corpo/dono, o warah do grupo seria como seu "tronco" em torno do qual as pessoas viveriam juntas, ocupando a posição daquele que é capaz de angariar a ação das pessoas

4 Para saber mais sobre o tema ver Amoroso (2011). 
em conjunto e em benefício do coletivo (Ibid.: 184). Da mesma forma, o anetü seria o "esteio da gente" (kuge iho), aquele que confere o suporte de uma criação, descrição que não resume apenas ao cargo de chefe, mas alcança todas as relações baseadas no cuidado e na nutrição. A exemplo disso, o marido deve ser o suporte de sua esposa, tal como o dever de um pai é dar amparo para seus filhos, nesse sentido, o chefe é o iho de seu povo (Ibid.: 156). Vemos como a imagem do apoio que sustenta uma casa ganha no discurso ameríndio a condição de potente metáfora para discernir os deveres e também as qualidades daquele que assume o lugar de chefe.

Quando voltamos novamente ao discurso mura, o tom jocoso da prosa do antigo tuxaua nos revela algo a mais sobre as qualidades de um bom chefe. Próprios ao dom da oratória mobilizada pelos chefes, autoridade e sedução devem caminhar juntas quando a missão é convencer os outros, traços que não podem estar ausentes de qualquer projeto de liderança. Necessárias, uma à outra, autoridade e sedução ou constância e movimento revelam-se como opostos que forjam a práxis da liderança comunitária. A bronca que vinha das outras aldeias destinadas ao atual chefe do Pacovão, não se resumia apenas ao governo da comunidade, mas também à falta de autoridade sobre seus filhos, acusados de fazerem "bagunça" em outras aldeias. Se a agência do tuxaua sobre o coletivo não dependia de dureza, o mesmo não era dúvida quando se dizia respeito a sua própria residência. Para realizar o papel de chefe era necessário algo a mais. Casa e aldeia pareciam se confundir nas falas dos tuxauas que equiparavam o poder e a jurisdição que mantinham sobre sua casa com aquela sobre a aldeia. Afirmação que ganha ressonância em outros contextos ameríndios, onde o chefe surge como um "pai adotivo" da aldeia (Guerreiro Junior, 2012: 155), chamando seu pessoal de "crianças" em seus discursos (Barcelos, 2008: 266). De certa maneira, o chefe assume a responsabilidade de criar uma comunidade de semelhantes, obrando para que todos trabalhem juntos, ele produz o parentesco entre elas, mesmo que momentaneamente como dizem os Kanamari (Costa, 2007: 184). Sabemos, entretanto que a distância de metáfora de casa para metonímia de aldeia impõe a diferença entre a criação/semelhança e a tensão/diferença. A autoridade que um pai exerce sobre seus filhos é monopólio da criação que concedeu existência a eles, uma prerrogativa que não se sustenta diante de vidas alheias. No limite, o tuxaua deseja ser o pai da aldeia, mas os aldeados não querem ser seus filhos, pois, para os Mura, parece que quem disciplina e comanda, é aquele que cria.

A discricionariedade exposta pelas intenções do chefe não era acompanhada de perto pela subserviência dos aldeados. O caso da separação dentro da aldeia Vila Nova também corrobora para esmiuçar a fórmula que colocamos no início. Meu último campo em 2015 abriu-se com a notícia da criação da aldeia São Pedro, o antigo tuxaua e fundador da aldeia Vila Nova levaria sua turma para fundar uma nova comunidade do outro lado do rio. O conflito gerado dentro da mesma parentela, mas correspondendo a turmas diferentes teria tomado tamanha proporção que a manutenção do convívio seria insustentável. Acusações de feitiçaria teriam dado o termo para a dissensão. $O$ evento em questão nos permite então, aprimorar a imagem do tuxaua como dono. O chefe mura não é dono do todo ou dono do grupo, é sobretudo dono da sua família. É nesse sentido que o tuxaua é o dono, pois o que está sob sua alçada pessoal, no caso sua turma, contem virtualmente a semente do conjunto das turmas. A passagem de uma turma para o conjunto das outras se faz com a capacidade de tor- 
nar os interesses da sua, os mesmos do restante da aldeia. Uma volta que, como sabemos, não está livre de desvios.

O que é matéria-prima de uma turma também deve sê-lo de toda uma aldeia, surgida da primeira, a última não passa de um conjunto de turma que guardam consigo uma origem comum. É a "consideração" que avigora os laços que existem entre os membros de uma turma, alimentados e atualizados cotidianamente, eles são constituídos pelos circuitos de trocas de alimentos, memória e cuidado (Autor, 2016). Contemplando o plano da aldeia, a relação do chefe com sua comunidade não deixa de carecer do mesmo conteúdo. Não quero dizer, para tanto, que exista um circuito de trocas materiais abarcando o conjunto de toda aldeia, mas a convivência com o todo existe sob esse mesmo discurso. A rede de obrigações e favores que entrelaça o caminho do conjunto das famílias de uma aldeia a casa do tuxaua não se resume, por isso, às turmas que ele encabeça ou das quais faz parte, existe para tanto, outros modos de convergir a atenção de todas as outras casas para o seu centro.

Contra a tristeza, sinônimo da dispersão, existe a alegria - hiato da labuta e da semana - ela é um modelo de conjunção ${ }^{5}$. Acentuar esse pormenor, sublinhando-a como uma força concêntrica, nos remete diretamente à descrição dos fins de semana da aldeia do Forno. A distribuição descontínua de suas casas, não concentradas sobre o mesmo pedaço de terra, limita aos últimos dias da semana a reunião da aldeia em torno do campo de futebol para a popular "brincadeira”. Lançando mão da aldeia do Forno como um modelo reduzido da chefia mura, tomamos a conformação da localização física de suas moradias como mais um elemento para pensar o problema da chefia: a conjunção de todas as turmas na turma do tuxaua.

A aldeia do Forno existia como manifestação tangível e visível em ocasião daqueles encontros, quando lograva convergir suas partes componentes para o seu terreiro. Comentava-me, o pai do tuxaua, antigo chefe e fundador da aldeia, sobre seu desejo de dispensar o dinheiro da poupança que mantinha guardada para bancar uma atração musical para a próxima Festa de Santo da aldeia. A afluência de todas aquelas casas, igualmente filhos/filhas, netos/netas, genros/noras para o terreiro da aldeia é o que torna a "autoridade" do chefe palpável. Imagem oposta à da separação que havia conflagrado a configuração atual da aldeia do Pacovão. Podemos ver como a centralização dos momentos de reunião contrasta diretamente com a imagem de descentralização da descrição anterior. Um quadro que tanto tinha relação com a inexperiência política da chefia do Pacovão quanto com sua incapacidade de manipular os futuros dos casamentos que tinha a sua disposição. Uma questão que não deixava de entrar na pauta de chefia do Forno, visto que mesmo ela já havia perdido alguns casais para outras aldeias. Ao fim, o desejo que me fora segredado pelo pai do tuxaua do Forno não era simplesmente aquele de um benfeitor, mas o do dono da alegria daquela comunidade. Produzir alegria, logo, parecia ser também um fator político. Subproduto da "consideração", a alegria incentiva as relações que conectam todas aquelas casas a seguir em seu movimento ordinário. Vemos então, como se por um lado o chefe não mantém a guarda da tutela sobre os aldeados, como a tem sobre seus filhos, por outro, ele é a origem de um carisma passível de concentrar todos ao seu redor como o faz um avô que conta histórias aos seus netos.

5 A tristeza no rio Igapó-Açu existe enquanto sinônimo de solidão e morte. Diziam das situações em que a comunidade se esvaziava com a viagem de seus moradores para a cidade que a aldeia entrava em um clima "triste, triste e que até misura aparecia”. Um afeto que em outras regiões da Amazônia ganhava conotação de um mal que deve ser contido (Sauma, 2013). 
Podemos enxergar a comunidade como o desdobramento de um processo que se fundou sobre a experiência de habitar um lugar. Os laços ali fincados e distribuídos se traduzem na memória de se fazer naquele pedaço de terra. Os laços constituídos pela primeira turma são a matéria-prima dos laços das turmas seguintes. O tuxaua produz a comunidade tanto quanto essa o produz em contrapartida. A complexa rede de viventes estabelecida ali também era o acervo das memórias dos laços criados e gerados cotidianamente. O tuxaua surge então como dono desses laços porque ser chefe de uma aldeia também era cuidar deles, ou ao menos, ser o guardião da sua memória. Ao analisar a categoriachave de "dono" como um amplo espectro da sociologia ameríndia, Carlos Fausto a define como a forma singular de uma pluralidade (2008: 334). Uma relação de maestria que não se traduz na condição direta de comando-obediência entre dois seres, guardando antes uma "instabilidade constitutiva" que resulta em um perigo constante de reversão da posição entre os termos (Ibid: 343). Lemos um desfecho possível na parte da narrativa que contempla os dias atuais da aldeia Correia. Após ter perdido seus moradores para as áreas urbanas vizinhas, ela vivia um quase abandono. Resistia ainda o tuxaua, seu filho e mais a sua nora cuja existência reverberava a memória do que fora o berço de uma aldeia. A repetição de suas ações naquele espaço era um modo de manter vivos os laços que ainda poderiam desencadear o retorno de seus moradores. Tuxaua outrora de uma comunidade, o chefe era hoje refém da vontade daqueles que ali viveram com ele.

O tuxaua, ao assumir a condição de dono da sua turma/aldeia/laçosconstitutivos vê a si como peça chave no jogo de intenções que se movimentam em direções contrárias. Administrando as contingências que carregam consigo energias disjuntivas, ele deve mesclar, ou melhor, sobrepor seus interesses pessoais com aqueles em favor de uma ambicionada coesão do grupo. Uma predisposição que nem sempre se averigua na prática, visto que, por vezes, o chefe pretere o todo da comunidade em benefício de sua facção residencial. Do "fazedor de paz" [peacemaker] como descreve Robert Lowie sobre a posição do titular chief (1948), espera-se que encontre o equilíbrio da existência comum diariamente, domesticando os ânimos e as tensões, ele atua pela continuidade do grupo e mais especialmente, para o bem viver do mesmo. O risco que discussões e brigas coloquem parentes uns contra os outros não é apenas um problema político, mas um receio que cada morador guarda dentro de si com exasperação. Para tanto, como sabemos, parte da estratégia reside no jogo das alianças. Tendo ao seu alcance a possibilidade de manipulação de alguns casamentos chaves, aqueles que estão sob sua influência como pai de uma turma, ele tenciona converter a diferença - seus afins - em aliados. Segurando a residência deles em torno de sua órbita, seus genros vivem sob os encargos de uma relação hierárquica que se traduz em termos de parceria $^{6}$. Uma trama que, como demos a perceber, possui mais reveses que avanços.

Diante da face interna que desloca a instituição da chefia para o campo do parentesco, como fundamento da atualização dos componentes que o estruturam, ressalta-se a necessidade de discutir a face externa de sua posição. Critica-

\footnotetext{
${ }^{6}$ Parceria é um regime político e cosmopolítico de relação que envolve termos opostos, ou melhor, diferenças que se estabelecem tanto entre humanos, entre não humanos e, finalmente entre humanos e não humanos. Uma relação privilegiada que se funda em um contrato não formal do qual a distância imposta pelas diferenças é substituída pela proximidade e um esvaziamento de tensões latentes. "Cosmopolítico" vem da noção de Bruno Latour, tomada emprestado da filósofa Isabelle Stengers, para pensar o alargamento dos significados da política e do cosmos quando juntos criam uma nova esfera de atuação e relação (2004: 454). Para esse artigo, longe de adentrarmos no campo das relações cosmopolíticas, fixamos nossa atenção no rendimento da categoria de parceria nas relações humanas tecidas no espaço intracomunitário e intercomunitário, matéria prima por excelência do ofício de chefia.
} 
do pelo jogo político que forja no interior, questionado pelo dúbio posicionamento que toma em questões de ordem comunitária, condenado por soluções que satisfazem apenas a sua parcela interessada, "resta ao chefe só sua condição de intermediário com o exterior" (Calávia Sáez, 2006: 147). O chefe é o representante mura no exterior, um intermediário que estabelece a comunicação entre o mundo dos brancos e o mundo dos indígenas. Portador dos interesses Seus e dos Outros fora, permanece dentro com a reputação sentenciada por cuidar apenas dos Seus. A posição controversa do tuxaua, entretanto não lhe impede de lutar pelos recursos ditos indispensáveis ao seu povo. Uma função que, quando exercida com esmero é a principal fonte de prestígio e reconhecimento de uma liderança.

No contexto político do rio Igapó-Açu, os Mura são classificados pelos órgãos competentes da administração municipal como uma população indígena, as quais são previstos os investimentos destinados à formação de pessoal e construção de equipamentos adequados. As demandas nativas então, sobre saúde e educação diferenciadas pesavam como moedas da negociação que colocavam em relação as lideranças locais e o poder público. Sua ação global, muitas vezes atendendo o anseio de todas as comunidades, contudo, não se furtava à intermediação de objetivos individuais como alguns apontavam, remetendo-se então à figura de alguns chefes. Nesse mesmo campo, ainda assim, a intercessão do tuxaua também era indispensável para a resolução de alguns problemas burocráticos, sua presença como pessoa pública era exigida e sintetizada pela assinatura de documentos de representação legal junto aos interesses de indígenas.

\section{O limite da chefia mura}

Em sua análise com referências de modelos de chefia pelas terras baixas da América do Sul, Clastres oferece uma reelaboração das três propriedades fundamentais da chefia descritas por Lowie. Segundo o último, o chefe, além de um apaziguador de conflitos, deveria ser generoso e bom orador; Clastres acrescentaria finalmente o privilégio de deter o direito à poliginia (2003 [1974]: 55). Esses três elementos fundamentais; a troca de bens, as mulheres e as palavras estruturam a existência da comunidade, constituindo o próprio "cerne do universo da comunicação" (ibid: 57). Por desviá-los de modo unidirecional, a posição da chefia é deslocada do seio da sociedade/cultura que, para poder subsistir, deve ser regida pela reciprocidade. É exatamente por oferecer um risco ao fundamento da sua existência que a chefia deve permanecer na periferia da sociedade. Classificada com o mesmo grau de ameaça que oferece a natureza, resta à sociedade isolar a ação e o pensamento da chefia do corpo do grupo para assegurar a sua impotência (ibid: 61).

O modelo da chefia mura, baseada nos casos específicos expostos, é um reflexo dos fundamentos antevistos por Lowie. Como pacificador, o tuxaua assume por vezes o papel de canalizador de crises internas sem, contudo, interferir diretamente sobre elas. A capacidade de oferecer boas palavras, apesar de prérequisito para qualquer liderança, acaba por destacar alguns chefes do rio Igapó-Açu em relação a outros. Por fim, a generosidade que não se traduz necessariamente na circulação material de bens, porém mais diretamente à disposição da chefia às demandas alheias, sejam individuais ou coletivas. Agora, quando tocamos no caso do privilégio da poliginia, ele também ganha referência empírica dentro do quadro dos chefes do Igapó-Açu. Falar do modelo representado pe- 
lo tuxaua da aldeia do Piranha é tratar da figura de exceção que a posição da chefia define, bem como, falar da passagem que possibilita a concentração do poder sobre uma pessoa, a construção do sujeito "magnificado" e a emergência de um projeto de Estado (Sztutman, 2012).

Todas as manhãs, o tuxaua da aldeia do Piranha encontrava-se no mesmo lugar. A frente de sua residência, sentado em um banco, ele elevava sua voz sobre os temas que importavam para a opinião pública. Igualmente, todas as manhãs era possível acompanhar o movimento da última geração de seus filhos que seguiam em direção a sua casa, a casa focal da turma a qual pertenciam. Lá estavam eles, assim como outros cujos caminhos de suas respectivas turmas acabavam se cruzando com aquela. O que deveria ser uma reunião de família para compartilhar do café da manhã, era na verdade uma ocasião para narrativas do passado, histórias atuais ou resolução de pendências. Todos os presentes atendiam ao discurso matutino do chefe sem, no entanto, acudi-lo, já que escutavam sem atenção. Em razão do caráter moralizante da sua fala, era menos um discurso para sua turma do que para toda a aldeia, apesar do alcance das suas boas palavras não serem ouvidas diretamente pelo restante dos aldeados. Acolhida ou não, era uma fala que jamais deixava de ser pronunciada. O que era emitido com uma voz mansa e calma muitas vezes se afiançava na memória dos mais velhos, no tempo dos "troncos velhos", dali retirando parábolas que deviam ser vivenciadas ou, simplesmente, elogios aos bons tempos que acabaram. "Celebrações da história" como se referiria Bruna Franchetto aos discursos kalapalo (1993), peças que marcam referências em torno de eventos para pensar uma história particular, segundo critérios culturais específicos (Ibid.: 104). Circunscrevendo eventos marcantes, as histórias do tuxaua conotavam uma experiência particular com aquele mundo, qualificando sua posição e demarcando a história de todo aquele coletivo.

Principal liderança dentro do rio Igapó-Açu, destacava-se nas negociações que envolviam o poder público e a relação com os brancos. Considerado artífice da efetivação dos direitos por saúde e educação diferenciada, ele angariava influência, não deixando, contudo, de ser uma figura controversa. Dono de um fala mansa e articulada, ele ainda era conhecido por ter ostentado o privilégio da poliginia. Motivo de polêmica diante de um costume em desuso revela, na verdade, o mecanismo de sua inserção na comunidade da qual não era originário. A aliança matrimonial com duas irmãs da turma de fundação da aldeia do Piranha teria encaminhando sua investidura como chefe. Tal como o discurso dos outros tuxaua do rio Igapó-Açu, sua posição era manca de qualquer expressão de comando. O domínio do social revela-se a todo instante como também o domínio do político, mas para a chefia é um espaço estéril às suas pretensões, sejam elas devotadas ao benefício coletivo ou particular. Vigiado, o lugar do chefe é constrangido não pela disputa, mas pela desconfiança mútua.

O discurso e ação da chefia restringem-se como atos de persuasão e apaziguamento, jamais de poder. Por trás da imagem de benfeitor e de tomador de iniciativas, encontra-se a missão sempre inglória de confluir o caminho de todas as turmas à sua. Sua necessidade de estar em todos os lugares a todo o tempo, termina por colocá-lo em lugar nenhum. Seu movimento guarda em sua origem um contramovimento, o contrafluxo dos desejos e deliberações pessoais daqueles que residem sobre a mesma terra que ele. Os laços que o fundador da aldeia mantém com aquele lugar são da mesma natureza que os daqueles que convivem com ele, sustentá-los é também de algum modo manter os laços dos outros. Assegurar sua posição enquanto chefe significa então garantir igualmente a 
existência da comunidade. Contudo, não nos escapa de vista a imagem do domínio do social como um espaço acossado a todo o momento por forças descentralizadoras. Sua condição imanente de espaço político reside no fato de estar preenchido por múltiplas forças, contrapoderes que contestam e lidam com a proeminência dos interesses da chefia ou de uma facção. O limite da união, logo, é flexionado por movimentos rizomáticos que encontram no tuxaua um obstáculo para seu progresso ${ }^{7}$. Sua ciência se empenha para ampliar a influência de uma agência centrífuga capaz de produzir coesão e gerar atração. O faz sem poder, sem autoridade, sem qualquer instrumento de coerção, como concluía Clastres, pois "o espaço da chefia não é o lugar do poder" (2003 [1974]: 218). Como sublinha Renato Sztutman, uma das grandes contribuições da obra do antropólogo francês refere-se ao alargamento da noção do que é político, posto que a "ação política" deixa de ser uma busca pelo poder, para também abarcar um modo de combatê-lo (2012: 41).

Os direitos às condições de assistência médica e os subsídios necessários à promoção de uma educação diferenciada não eram artefatos apenas das negociações envolvendo brancos e índios. Depois de conquistados, dentro do rio Igapó-Açu, eles eram um argumento a favor da agência política manuseada entre os tuxauas. Quando nos voltamos para o contexto da Amazônia peruana, entre os Piro do Baixo Urubamba, vemos como as comunidades dali passaram a centralizar-se em torno das escolas após suas instalações, em vez da figura dos chefes como era de antemão (Gow, 2001: 242). Um potencial que era do mesmo modo visionado pelas lideranças do rio Igapó-Açu que disputavam a localização das instalações escolares e de atenção à saúde. No discurso nativo, como já sublinhado, o embate era colocado em termos de quem tinha mais força. Quem tinha mais "força puxava" mais famílias para morar junto de si, mais família sob a órbita de sua fala. Mais famílias significavam também mais recursos disponíveis e, portanto, mais influência política.

Nesse quadro geopolítico, a iniciativa do tuxaua da aldeia do Piranha se sobressaía. Apontavam para ele, acusando que, se dependesse de sua vontade, "todas as aldeias se mudariam para lá [no Piranha]". Por trás dessa vontade ocultava-se a ameaça radical do Um, a essência universal do Estado (Clastres, 2003 [1974]: 229-230). Seu desejo era a pulsão de um processo que o havia produzido como um sujeito de muitas turmas. Os laços constitutivos que atualizavam sua relação com sua turma e, por conseguinte com sua aldeia somavamse, por sua vez àqueles que agregavam outras turmas e, desse modo, também outras aldeias. Seu papel como liderança local e os feitos que lhe angariavam prestígio entre as outras comunidades haviam dado alcance para uma pessoa "magnificada", ou seja, um "acumulador de relações" que o projetavam para além do domínio em que foi gerado (Sztutman, 2012: 151). Esse parece ser o projeto por trás do esquema de montar todas as aldeias em um mesmo lugar.

O tuxaua é aquele que cria sua turma e junto dela se cria, os laços cognáticos que englobam as outras turmas sobre o chão da mesma comunidade são dominados pelos valores da criação e do cuidado, gestados já de antemão no interior de cada turma; a convivência que atualiza diariamente o ideal de uma parentela comum. Ao projetar-se para além de seu círculo familiar, o tuxaua en-

\footnotetext{
7 Aplicamos aqui a noção de Gilles Deleuze e Félix Guattari como inspiração, pois mais do que um conceito ela é a descrição de um modelo de resistência, tais como outras formações de "direções movediças" também o são (2000 [1980]: 31). Assim, a aldeia mura é um rizoma porque os fluxos de oposição criados pelos interesses conflitantes das pessoas que nela vivem contrariam as intenções totalizadoras demonstradas pelo seu chefe. Como os autores definem todo rizoma compreende segmentações, tornando-o "estratificado, territorializado, organizado, significado, atribuído, etc", mas igualmente carrega dentro de si "linhas de desterritorialização", desmembrando o conjunto para fugir dele (idem: 18).
} 
globa outras pessoas em torno si, um lastro de laços que visa em seu limite uma totalidade. Um perigo que um profeta guarani, resguardado em meio a uma floresta no Paraguai, já havia divisado e sublinhado para Clastres, aquele representado pela falácia do Um. A erupção de um limite, sintetizado por um modo de existência baseado sobre "o transitório, o passageiro e o efêmero" que tende sempre para o esgotamento completo (2003 [1974]: 187). Revelando a impossibilidade de agregar toda a diferença: motor da criatividade local e matéria da reprodução social. O absurdo é representado por aquele ideal de unir todas as turmas em uma - uma divisa e uma divisão - a primeira contra as vontades alheias e a segunda entre o chefe e a comunidade. Um estado que jamais se alcança, seja porque a aldeia está diante de forças disruptivas que tencionam contratos de alianças estabelecidos, puxando filhos e filhas para morar em outras comunidades, ou mesmo porque jamais deixa de pairar uma desconfiança entre os aldeados e o seu tuxaua. Isso era claro, por exemplo, para todo o prestígio e influência que recaía sobre imagem do tuxaua do Piranha, sobre o qual vigorava do mesmo modo e a contrapelo, acusações de uso de feitiçaria. A estabilidade, independente de sua escala, é um horizonte inalcançável.

\section{Considerações finais}

O chefe é representante de uma posição que precisa ser ocupada dentro do espaço de constituição de uma aldeia, pois não existe aldeia sem chefe. De certo, tanto o nascimento como o esfacelamento de uma aldeia passam pelas prerrogativas e expectativas em torno da atuação de um chefe, contudo, a própria vida da comunidade também passa ao largo de suas intenções. Como um grupo se mantém e como ele prospera pode ou não resultar da capacidade de articulação e mobilização de um bom chefe; um bom trabalho, aquele que é conduzido sob os auspícios de um tuxaua respeitado, também se espelha na disposição de seus aldeados em conviver juntos. Ainda assim, o cotidiano de uma aldeia e a própria dinâmica social na qual ela está imersa depende da agência de outros componentes. Podemos destacar nesse cenário, por exemplo, o papel do pajé e dos benzedores que se colocam como mediadores das relações estabelecidas entre o grupo e os mundos que existem contiguamente a ele. Funções fundamentais que dizem respeito tanto à saúde das pessoas que ali residem, como mesmo da condição humana que encontrou naquele lugar um nicho para coexistir em um mundo de adversidades. Destaca-se também, o lugar das mulheres nesse contexto, como já apontamos alhures (Autor, 2019), as mulheres de uma comunidade e dentro das diferentes facções residenciais que a compõem, existem como vetores do processo de humanização. A atuação das mulheres mura transborda o espaço doméstico para realizar-se como modos de controle e englobamento da diferença, deixando transparecer sua influência silenciosa sobre a existência comum. Nesse quadro, a manifestação das faculdades inerentes à posição da chefia ganha, por vezes, maior relevo na relação com o mundo exterior, não me referindo apenas àquele pertencente aos brancos, mas igualmente ao plano que coloca em comunicação os outros tuxaua do rio Igapó-Açu. O tecido político que enreda o conjunto intercomunitário oferece um novo enquadramento para pensar a chefia mura. Baseado nos pontos de tensão e aproximação que se criam nos contatos estabelecidos entre as aldeias, visualiza-se especularmente a imagem que já se reproduzia no interior da comunidade, aquela de um personagem pródigo em ambição e desconfiança. 
Originada de uma contingência, gestada como um subproduto da criação, a chefia mura encontra vias para se degenerar em um projeto pessoal. A metáfora do mastro rijo entregue pelo antigo tuxaua da aldeia do Pacovão oculta algo detrás do riso fácil daquele que a emitiu. $\mathrm{O}$ mastro tem que estar duro para sustentar a comunidade sob a sua égide, mas o "duro" era igualmente uma metáfora sexual, dela discernia-se o dom da fertilidade que sua vontade trazia consigo ao dar início no que se desabrocharia como uma comunidade. Uma relação filiativa, comparável aquela entre pais e filhos e que se desdobraria em uma relação de aliança, desbastada pelo trato entre sogros e genros/noras. Se a primeira é alimentada pelo afeto, cuidado e memória, a segunda é norteada pela desconfiança. A mesma desconfiança narrada no início entre os moradores e o tuxaua da aldeia Jutaí é a aquela fomentada entre os Mura e suas lideranças.

A perspectiva sobre a prática dos diferentes tuxaua do Igapó-Açu possibilitam ver um quadro movimentado por estabilizações e desestabilizações. Forças centrípetas e centrífugas que são relativas à escala do socius observada. Nesse sentido como apontam Tânia Stolze Lima e Marcio Goldman ao comentarem a obra de Clastres, o próprio exercício da chefia revela sua face agregadora e desagregadora no espaço de modulação entre o intracomunitário e o intercomunitário (2003: 21-22). Falar da chefia mura é tratar do nascimento e morte de uma comunidade. $\mathrm{O}$ chefe nasce com sua comunidade e, aparentemente se entrega à morte junto com a mesma. Essa parece ao menos, a sina do tuxaua da aldeia Correia que reside na esperança de rever a alegria que nutria da época em que morava com os seus parentes. Para o olhar estrangeiro, daqueles que vivem na cidade de Borba, as gentes do Igapó-Açu são reconhecidas como a turma do Tcheré. Um coletivizador que entrega a imagem distorcida do espelho que reflete a vontade do tuxaua da aldeia do Piranha. O Um também é um reflexo.

Recebido em 19 de agosto de 2018.

Aprovado em 2 de abril de 2019.

\section{Referências}

AMOROSO, Marta R. O ambientalismo e as novas negociações dos Mura do rio Preto do Igapó-Açu (AM). Revista do Museu de Arqueologia e Etnologia. São Paulo, USP, v. 11, 2011, p. 11-24.

. O nascimento da aldeia mura: sentidos e modos de habitar a beira. In: AMOROSO, M. e MENDES DOS SANTOS, G. (org). Paisagens Ameríndias: lugares, circuitos e modos de vida na Amazônia. São Paulo: Terceiro Nome, 2013, p. 93-114.

BARCELOS NETO, Aristóteles. Apapaatai: Rituais de Máscaras no Alto Xingu. São Paulo: EDUSP/FAPESP, 2008.

CLASTRES, Pierre. Copérnico e os Selvagens. In: CLASTRES, Pierre. Sociedade Contra o Estado. São Paulo: Cosac\&Naify. 2003 [1974], p. 25-45.

. Do Um sem o Múltiplo. In: CLASTRES, Pierre. Sociedade Contra o 
Sociedade Contra o Estado. In: CLASTRES, Pierre. Sociedade Contra o Estado. São Paulo: Cosac\&Naify. 2013 [1974], p. 201-231.

COSTA, Luiz Antonio. As Faces do Jaguar. Parentesco, História e Mitologia Entre os Kanamari da Amazônia Ocidental. Tese de Doutorado, Antropologia Social, UFRJ, 2007.

DELEUZE, Gilles \& GUATARRI, Félix. Mil Platôs Capitalismo e Esquizofrenia. Vol 1. São Paulo: Editora34. 2000 [1995]

FAUSTO, Carlos. Donos demais: maestria e domínio na Amazônia. Mana. Estudos de Antropologia Social, Rio de Janeiro, MN, vol. 14, n. 2, 2008, p. 329-366.

Autor. No seio do rio: linhas que casam, que curam e que dançam. Parentesco e corporalidade entre os Mura do Igapó-Açu. São Paulo: Alameda, 2018.

Ele não sabia nada e elas ensinaram tudo - a agência das mulheres mura no processo de humanização. Tessituras: Revista de Antropologia e Arqueologia. Pelotas, Unipel, 2019, p. 172-191.

FRANCHETTO, Bruna. A Celebração da História nos Discursos Cerimoniais Kuikúro (Alto Xingu). In: VIVEIROS DE CASTRO, E e CARNEIRO DA CUNHA, M. (org.) Amazônia Etnologia e História Indígena. São Paulo: NHII/USP FAPESP, 1993, p. 95-116.

GUERREIRO JUNIOR, Antonio Roberto. Ancestrais e suas Sombras Uma Etnografia da Chefia Kalapalo e seu Ritual Mortuário. Tese de Doutorado, Antropologia Social, UnB, 2012.

GOW, Peter. Of Mixed Blood. Kinship and History in Peruvian Amazonia. Oxford: Claredon Press, 1991.

LATOUR, Bruno. Whose cosmos, which cosmopolitics? Comments on the Peace Terms of Ulrich Beck. Bruno Latour Common Knowlegde. In: Common Knowledge, vol. 10, Issue 3, 2004, p. 450-462.

LÉVI-STRAUSS, Claude. Tristes Trópicos. São Paulo: Cia das Letras. 2004 [1955].

LIMA, Tânia Stolze. Um peixe olhou pra mim: O Povo Yudjá e a Perpectiva. São Paulo: Ed. da UNESP/ISA/Nuti, 2005.

LIMA, Tânia Stolze \& GOLDMAN, Marcio. Prefácio. In: CLASTRS, Pierre. Sociedade Contra o Estado. São Paulo: Cosac\&Naify, 2003, p. 201-231.

LOWIE, Robert. Some Aspects of Political Organization among the American Aborigines. The Journal of the Royal Anthropological Institute of Great Britain and Ireland, Londres, RAI, vol. 78, N. 1/2, 1948, p. 11-24.

MAIZZA, Fabiana. Cosmografia de um Mundo Perigoso: Espaço e Relações de Afinidade entre os Jarawara da Amazônia. São Paulo: Edusp, 2012.

OVERING, Joanna. The Piaroa: A people of the Orenoco Basin. Oxford: Claredon Press, 1975.

OVERING, Joanna; PASSES, Alan. Introduction. In: OVERING, Joanna; PASSES, Alan (Eds). The Anthropology of Love and Anger, The Aestheics of Conviviality in Native Amazonia. London: Routledge, 2000. 
SAUMA, Julia F. - The Deep and the Erepecuru: tracing transgressions in an Amazonian Quilombola Territory. Tese de Doutorado, Antropologia Social, LSE, 2013.

SEEGER, A., DA MATTA, R. \& CASTRO, E.B.V. DE. A construção da pessoa nas sociedades indígenas brasileiras. Boletim do Museu Nacional, Rio de Janeiro 32, 1979, p. 2-19.

VIVEIROS DE CASTRO, Eduardo. Araweté: os Deuses Canibais. Rio de Janeiro: Jorge Zahar/ANPCS, 1986. 